\title{
ANALISIS LAYANAN PENGADAAN BARANG DAN JASA SECARA ELEKTRONIK (LPSE) PADA KANTOR KOMUNIKASI DAN INFORMASI KABUPATEN MAROS
}

\author{
Moch. Ali Mashuri ${ }^{1}$
}

\begin{abstract}
This study's objectives are to describe and analyze the transparency and the factors affecting transparency in the Electronic Procurement of Goods and Services at the Department of Communication and Information in Maros Regency. The research used qualitative approach. Based on the analysis, it is found that the aspect of transparency indicators in general has shown that LPSE service system transparent enough. There are some influential factors, including communication (miscommunication and misunderstanding between the committee and the company), technology (unstable internet connection), human resources (lack of good character or mental attitude among the people giving LPSE services), LPSE bureaucratic staffs who still have double positions at the Office of Communication and Information in Maros regency, the opinion among business community that the policy of transparency is still less effective and efficient in the process of procurement of goods and services, and the users of LPSE who still have limitation in using e-procurement of goods and services, and the users of LPSE who still have limitation in using e-procurement system.
\end{abstract}

Keywords: Transparency, e-Procurement, Electronic Procurement of Goods and Services

\begin{abstract}
ABSTRAK
Penelitian ini bertujuan untuk mendeskripsikan dan menganalisis transparansi layanan dan faktor-faktor yang mempengaruhi transparansi dalam Layanan Pengadaan Barang dan Jasa Secara Elektronik (LPSE) di Kantor Komunikasi dan Informasi Kabupaten Maros. Penelitian ini menggunakan pendekatan kualitatif. Hasil analisis menunjukkan aspek indikator transparansi secara umum telah memperlihatkanlayanan LPSE cukup transparan. Sementara berdasarkan faktor-faktor yang mempengaruhinya yakni faktor komunikasi antara panitia dan perusahaan terjadi miskomunikasi dan misunderstanding, faktor teknologi yang mana internet belum stabil, faktor sumber daya manusia yang diperlihatkan oleh kurangnya karakter atau sikap mental aparatur pemberi pelayanan LPSE, struktur birokrasi LPSE yang masih merangkap jabatan dengan staf di Kantor Komunikasi dan Informasi Kabupaten Maros, faktor keberterimaan masyarakat bisnis terhadap kebijakan transparansi masih kurang efektif serta efisien dalam proses layanan pengadaan barang dan jasa, serta faktor pengguna LPSE yang masih kurang maksimal dalam menggunakan sistem e-procurement.
\end{abstract}

Kata Kunci: Transparansi, e-procurement, LPSE

\footnotetext{
${ }^{1}$ Dosen FISIP Universitas Pembangunan Nasional ‘Veteran’ Jawa Timur, email: mashuriz@yahoo.co.id
} 


\section{PENDAHULUAN}

Pemanfaatan Teknologi Informasi dan Komunikasi (TIK) dalam menunjang kebutuhan masyarakat telah menciptakan berbagai peluang yang diharapakan dapat menghadirkan inovasi untuk meningkatkan kualitas pelayanan pemerintah khususnya pelayanan masyarakat umum, masyarakat bisnis, dan juga sesama lembaga pemerintah. Pemanfaatan TIK juga diharapkan dapat meningkatkan efisiensi, efektivitas, transparansi, dan akuntabilitas penyelenggaraan pemerintah khususnya dalam pengadaan barang dan jasa pemerintah.

Transparansi merupakan prinsip yang menjamin akses atau kebebasan bagi setiap orang untuk memperoleh informasi tentang penyelenggaraan pemerintahan, yakni informasi tentang kebijakan, proses pembuatan dan pelaksanaannya, serta hasil-hasil yang dicapai (Krina, 2003). Menurut Kim (2007), adapun unsur-unsur transparansi meliputi: kejelasan (clarity) dalam arti mudah dipahami/dimengerti oleh masyarakat, aksesibilitas (accessibility) dalam arti adanya pertukaran informasi dua arah, integrasi (integration) dalam arti dapat menjelaskan dan memberikan informasi tambahan yang dibutuhkan masyarakat, serta rasional (rationality) dalam arti adanya proses yang konsisten, terstandarisasi, formal, dan dapat diupgrade. Berdasarkan beberapa pandangan tentang indikator pengukuran transparansi, berikut indikator yang sesuai dengan kondisi realita di LPSE Kabupaten Maros khususnya pengadaan di Kantor Komunikasi dan Informasi Kabupaten Maros yang akan digunakan sebagain kajian atau pisau analisis, diantaranya adalah: menurut Dwiyanto (2006), menunjuk pada seberapa mudah peraturan dan prosedur pelayanan dapat dipahami oleh pengguna dan stakeholder; menurut Asian Development Bank (1999), data tersebut harus bebas didapat dan tersedia (freely and readily available); menurut IDASA dalam Andrianto (2007), adanya audit yang independen dan efektif; menurut Ratminto dan Winarsih (2014), persyaratan teknis dan administratif pelayanan, adalah persyaratan keikutsertaan tendering penyedia pada lelang di Kantor Komunikasi dan Informasi Kabupaten Maros; menurut Ratminto dan Winarsih (2014), Rincian Biaya Pelayanan, merupakan rincian biaya dalam proses layanan pengadaan barang dan jasa di Kantor Komunikasi dan Informasi Kabupaten Maros; menurut Asian Development Bank (1999), Akses pada informasi yang akurat dan tepat waktu (accurate and timely); serta menurut Smith (2004), pejabat yang 
Moch. Ali Mashuri - Analisis Layanan Pengadaan Barang dan Jasa Secara Elektronik...

berwenang dan bertanggung jawab/ Appeal rights.

Perkembangan LPSE di Kabupaten Maros yang merupakan salah satu kabupaten yang menjadi percontohan kota/kabupaten metropolitan di Sulawesi Selatan adalah atas dasar hukum pembentukan LPSE Pasal 111 Nomor 54 Tahun 2010 tentang pengadaan barang/jasa pemerintah yang ketentuan teknis operasionalnya diatur oleh peraturan kepala LKPP Nomor 2 Tahun 2010 tentang Layanan Pengadaan Secara Elektronik (LPSE). LPSE dalam menyelenggarakan sistem pelayanan pengadaan barang/jasa secara elektronik juga wajib memenuhi persyaratan sebagaimana yang ditentukan dalam undang-undang nomor 11 tahun 2008 tentang informasi dan transaksi elektronik. Layanan yang tersedia dalam sistem pengadaan secara elektronik saat ini adalah e-tendering yang ketentuan teknis operasionalnya diatur dengan peraturan kepala LKPP nomor 1 tahun 2011 tentang tata caraE-Tendering. Kemudian peraturan Bupati Maros Nomor 12 Tahun 2013 Tentang Standar Operasional dan Prosedur (SOP) Layanan Pengadaan Secara Elektronik (LPSE) Kabupaten Maros.

Pemerintah Kabupaten Maros telah mengukir banyak prestasi di tingkat nasional. Mulai dari
penghargaanInnovation Government Award (IGA) 2013 dengan kategori tata kelola pemerintahan yang baik dari Kementrian Dalam Negeri. Kali ini, berhasil meraih penghargaan $e$ Procurement Award 2014. Penghargaan ini diberikan atas apresiasi terhadap proses pengadaan barang secara transparan dan akuntabel yang dilakukan Pemerintah Kabupaten Maros. Namun, berdasarkan observasi awal dilapangan serta informasi dari salah satu informan pada Kantor Komunikasi dan Informasi Kabupaten Maros bahwa peneliti menemukan fenomena yang dihadapi oleh Pemerintah Kabupaten Maros dalam hal transparansi pengadaan barang dan jasa, masih terjadinya syarat akan persekongkolan dan kepentingan oknum tertentu, kadang menunda pengumuman lelang secara tiba-tiba serta ada group yang di setting oleh kelompok kerja untuk dimenangkan tendernya.

Berikut penelitian terdahulu yang menjadi sumber rujukan yakni penelitian tesis Herman (2015), dengan judul akuntabilitas Publik Dalam Pengadaan Barang/Jasa Pemerintah Secara Elektronik (E-Procuremet) Di Kabupaten Toraja Utara. Kemudian penelitian tesis Sani (2011), dengan judul evaluasi penerapan E-Procurement pada Pemerintah Provinsi Sulawesi Selatan. 
Berdasarkan latar belakang tersebut maka rumusan masalah penelitian ini adalah bagaimana transparansi Layanan Pengadaan Barang dan Jasa Secara Elektronik (LPSE) serta faktor-faktor yang memengaruhi transparansi dalam Layanan Pengadaan Barang dan Jasa Secara Elektronik (LPSE) di Kantor Komunikasi dan Informasi Kabupaten Maros.

\section{METODOLOGI PENELITIAN}

\section{Lokasi dan Objek Penelitian}

Penelitian ini mengambil lokus pada Kantor Komunikasi dan informasi, unit LPSE serta Unit Layanan Pengadaan (ULP) Kabupaten Maros. Alasan memilih lokasi tersebut adalah dengan memperhitungkan aksesibilitas, dimana lokasi penelitian mudah untuk dijangkau, dan memberikan peluang yang cukup karena tidak mungkin hanya diteliti dalam sekali waktu saja. Selain itu realitas yang diteliti masih terjadi (berlangsung).

\section{Pendekatan dan Jenis Penelitian}

Penelitian ini menggunakan pendekatan kualitatif dengan alasan bahwa temuan-temuan dalam penelitian kualitatif tidak diperoleh melalui prosedur statistik atau bentuk hitungan lainnya dalam Moleong(2012).Pemilihan jenis penelitian ini mengacu kepada pandangan Stake dalam Cresweell
(2010), yang menyatakan bahwa case studymerupakan strategi penelitian dimana di dalamnya peneliti menyelidiki secara cermat suatu program, peristiwa, aktivitas, proses atau kelompok individuindividu.

\section{Informan}

Informan dalam penelitian ini yakni Kepala Kantor Komunikasi dan Informatika Kabupaten Maros, Kepala Sub Bidang Aplikasi Dinas Komunikasi dan Informatika Kabupaten Maros,Ketua LPSE Kabupaten Maros,Kepala Unit Layanana Pengadaan (ULP) Kabupaten Maros, Kelompok Kerja Unit Layanan Pengadaan (ULP),Pejabat Pembuat Komitmen (Pokja), Penyedia tender (perusahaan yang mengikuti tender layanan pengadaaan barang dan jasa yaitu CV. Masindo Network, CV. Tekno Prima, dan CV. Digital Solution).

\section{Teknik Pengumpulan Data}

Dalam penelitian ini, teknik pengumpulan data yang digunakan untuk saling melengkapi di dalam penelitian ini adalah: Teknik Wawancara, Teknik Observasi, dan Studi Dokumentasi.

\section{Teknik Pengolahan Data dan Analisis}

\section{Data}

Dalam penelitian kualitatif pengolahan dan analisis data merupakan kegiatan yang tak terpisahkan. Hal ini dapat dilihat pada tahap-tahap analisis data kualitatif dalam Sugiyono 
Moch. Ali Mashuri - Analisis Layanan Pengadaan Barang dan Jasa Secara Elektronik...

(2011),yaitu: reduksi data, penyajian data,

dan

penarikan

kesimpulan/verifikasi.

\section{HASIL PENELITIAN}

\section{Analisis Transparansi Dalam Layanan}

\section{Pengadaan Barang dan Jasa}

SecaraElektronik di Kantor Komunikasi

dan Informasi Kabupaten Maros

Berikut verifikasi indikator transparansi layanan LPSE dalam hal pengadaan di SKPD Kantor Komunikasi dan Informasi, yakni: menunjuk pada seberapa mudah peraturan dan prosedur pelayanan dapat dipahami oleh pengguna dan stakeholder yang lain; Data tersebut harus bebas didapat dan tersedia (freely and readily available); Adanya audit yang independen dan efektif; Persyaratan Teknis dan Administratif Pelayanan; Rincan Biaya Pelayanan; Akses pada informasi yang akurat dan tepat waktu (accurate and timely); Pejabat yang berwenang dan bertanggung jawab/Appeal rights di dalam penerapan e-Procurement di Kabupaten Maros.

Seberapa mudah peraturan dan prosedur pelayanan dapat dipahami oleh pengguna dan stakeholder yang lain untuk pelaksanaan peraturan dan prosedur dalam pengadaan barang dan jasa di lingkungan Kantor Komunikasi dan Informasi Kabupaten Maros sudah bisa dikatakan bagus dan efektif pada tahap pelaksanaan pengumuman pascakualifikasi yang mana mengumumkan segala informasi persyaratan dan prosedur dalam mengikuti lelang.

Menurut informan yakni kepala LPSE Kabupaten Maros bahwa:

"Peraturan dan prosedur pelayanan pengadaan dilaksanakan oleh Pokja atau Unit Layanan Pengadaan (ULP) dibawah Sekretariat Daerah (Kabag Pembangunan). Prosedurnya juga terlihat jelas di website LPSE Maros sebelum mengikuti lelang pengadaan barang dan jasa. Penyedia melakukan pendaftaran di LPSE maros dengan menyetujui pakta integritas dan memenuhi syarat dan ketentuan agar bisa mendapatakan user id dan pin untuk login penyedia. Berikut gambar websitenya di alamat (http://inaproc.lkpp.go.id/eproc/Syara tKetentuan2) (wawancara $4 \mathrm{Mei}$ 2015)".

Data-data pengadaan barang dan jasa pemerintah harus bebas didapat dan tersedia (freely and readily available) agar memudahkan penyedia untuk mendapatkan pelayanan prima dan juga pemerintah dalam memberikan pelayanan kepada masyarakat khususnya masyarakat bisnis. Data SPPJ dan Penandatanganan Kontrak hanya bisa diperoleh dan dilihat oleh penyedia yang menang tender. Jadi yang terlibat disini adalah Pejabat Pembuat Komitmen, Penyedia, dan staf atau tenaga ahli yang akan mengerjakan proyek lelang tersebut 
dan tidak semuanya bebas akses dan orang-orang tertentu.

Adanya audit yang independen dan efektif disini kontrol dilakukan untuk mencegah praktik-praktik kecurangan yang terjadi di dalam setiap tahapan dan proses pengadaan barang dan jasa pemerintah. Sehingga LKPP menciptakan mekanisme kontrol yang diberi nama Whistle blower System. Whistleblower System merupakan sarana baru yang dapat dimanfaatkan oleh penyedia barang dan jasa (rekanan) dan tentunya masyarakat (publik)untuk mengadukan penyimpangan yang terjadi dalam proses pengadaan barang dan jasa pemerintah, termasuk dugaan KKN. Whistleblower System merupakan sub sistem di dalam aplikasi SPSE, atau dapat diakses di www.wbs.lkpp.go.id. dan mudah di akses oleh publik dimanapun berada.

Untuk mewujudkan transparansi layanan pengadaan barang dan jasa salah satunya harus transparan dalam hal persyaratan teknis dan administrasi pelayanannya. Persyaratan teknis dan administrative pelayanan pengadaan barang dan jasa yang telah dipenuhi dengan baik oleh para pihak menandakan bahwa transparansi layanan pengadaan telah terwujud dengan baik.

Pada proses pengadaan barang dan jasa secara elektronik di Kantor Komunikasi dan Informasi Kabupaten
Maros tidak ada biaya yang dipungut dari pihak panitia. Untuk unsur biaya hanya lebih mengacu pada biaya internet atau pulsa masing-masing pihak penyedia.

Tahap terakhir yakni SPPJ yang diterbitkan pejabat pembuat komitmen dan penandatanganan kontrak telah sesuai dengan jadwal kegiatan dan dokumen sangat terpercaya dan legal menurut hukum. Dalam proses pengadaan barang dan jasa dari awal sampai keluar pemenang tender serta tanda tangan kontrak tender semuanya dilaporkan kepada Bupati Maros.

Faktor-faktor yang Mempengaruhi Transparansi di dalam Pengadaan Barang dan Jasa Secara Elektronik (LPSE) di Kantor Komunikasi dan

\section{Informasi Kabupaten Maros}

Dalam proses pengadaan barang dan jasa pemerintah khususnya di Kantor Komunikasi dan Informasi Kabupaten Maros bahwa ada beberapa faktor yang mempengaruhi transparansi dalam pengadaan barang dan jasa pemerintah, diantaranya adalah: faktor komunikasi antara penyedia dan panitia lelang. Faktor sumber daya yakni faktor teknologi yakni faktor teknis meliputi Server, sistem SPSE yang selalu upgrade dan faktor sumber daya manusia yakni faktor pengelola yang terdiri dari tim LPSE yang kapabilitasnya dan penguasaan atau 
pemahaman akan sistem yang ada. Faktor sikap aparatur pemerintah yakni para panitia lelang yang berstatus PNS masih syarat akan kemalasan, kurang loyal dengan waktu, dan kurang responsif terhadap tugas pekerjaannya. Faktor struktur birokrasi pemerintah yakni pengelola kebijakan LKPP dan LPSE merupakan unit pengadaan yang mana kantornya berada sama dengan Kantor Komunikasi dan Informasi Maros serta Ketua LPSE juga merupakan Kepala Kantor begitu juga pejabat LPSE lainnya merangkat jabatan dengan jabatan struktural Kantor Komunikasi dan Informasi. Faktor keberterimaan masyarakat bisnis terhadap kebijakan transparansi. Faktor penggunalayanan LPSE yakni faktor penggunaLPSE yakni Penyedia dan Kelompok Kerja ULP.

\section{PEMBAHASAN}

Penelitian ini menemukan bahwa transparansi layanan pengadaan barang dan jasa secara elektronik di Kantor Komunikasi dan Informasi Kabupaten Maros telah berjalan cukup transparan. Untuk memperjelas ciri dan penjelasan detail dari indikator dikatakan terpenuhi transparansi atau tidak terpenuhinya indikator transparansi dalam pengadaan barang dan jasa di Kantor Komunikasi dan Informasi Kabupaten Maros maka uraiannya sebagai berikut: Bahwa seberapa mudah peraturan dan prosedur dipahami oleh pengguna dan stakeholder adalah disetiap tahapan proses penentuan pemenang lelang memenuhi indikator ini dengan mudah dipahaminya peraturan dan prosedur oleh penyedia atau perusahaan dan juga panitia pengadaan sehingga indikator transparansi terpenuhi.

Data harus bebas didapat dan tersedia adalah bahwa tidak semua data dapat diperoleh dengan mudah atau transparan. Data-data pengadaan yang transparan antara lain: data pada tahap pengumuman pasca kualifikasi, pemberian penjelasan, dan pembuktian kualifikasi. Sedangkan data-data pengadaan yang tidak detail dan masih ditampilkan setengah-setengah bahkan dirahasiakan oleh panitia pengadaan diantaranya: data hasil evaluasi yang masih belum detail dan hanya diumumkan perusahaan yang lolos ke tahap selanjutnya, data pengumuman pemenang yang mana alasan penentuan pemenang lelang tidak detail atau masih perlu penjelasan oleh pokja dan itu harus melalui proses masa sanggahan selama 3 hari dan membuat penyedia tidak puas dengan penjelasan pokja, terakhir data SPPJ dan penandatanganan kontrak kerjasama antara pemenang tender dengan PPK yang tidak ditampilkan di website secara transparan dan hanya penyedia dan PPK yang mengetahuinya 
sehingga indikator transparansi dalam hal ini tidak terpenuhi.

Adanya audit yang independen adalah bahwa audit sudah dilakukan secara transparan dalam seluruh tahapan proses layanan lelang. Hal ini dilakukan evalusi secara online dengan Whistleblower System yang terhubung langsung dengan LKPP. Selain itu, langsung dipantau dan dievaluasi secara periodik oleh Inspektorat Daerah serta audit satu tahun sekali oleh BPK Sulawesi selatan dan BPK RI sehingga indikator transparansi terpenuhi.

Persyaratan teknis administratif pelayanan adalah bahwa segala persyaratan teknis dan administratif layanan pengadaan barang dan jasa dan seluruh tahapan telah berjalan transparan dengan diumumkannya setiap persyaratan atau kriteria tender melalui website LPSE Kabupaten Maros sehingga indikator transparansi terpenuhi.

Rincian biaya pelayanan adalah bahwa dalam pengadaan barang dan jasa secara elektronik tidak dipungut biaya apapun. Jadi, indikator transparansi tentang rincian biaya pelayanan ini tidak berlaku pada layanan lelang dengan sistem e-procurement.

Akses pada informasi yang akurat (valid) dan tepat waktu adalah bahwa seluruh tahapan lelang hingga muncul pemenang tender dan tanda tangan kontrak kerjasama berjalan secara transparan. Hal ini dilihat dilapangan bahwa segala informasi dan jadwal telah ditetapkan oleh tim pengadaan barang dan jasa sehingga keputusan pokja valid dan tepat waktu sesuai jadwal yang telah ditetapkan dalam rapat koordinasi tim LPSE yang sesuai dengan rencana pengadaan barang dan jasa di Kantor Komunikasi dan Informasi Kabupaten Maros.

Pejabat yang berwenang dan bertanggung jawab (Appeal Rights) adalah bahwa proses layanan pengadaan ada yang bertanggung jawab dan membinanya melalui Sekretaris Daerah Kabupaten Maros berdasarkan Surat Keputusan Bupati Maros Nomor: 27/KPTS/495/1/2015 tentang pembentukan tim Layanan Pengadaan Secara Elektronik (LPSE) Kabupaten Maros tahun anggaran 2015. Pada penetapan point kedua bahwa penanggung jawab LPSE Kabupaten Maros adalah Sekretaris Daerah Kabupaten Maros. Sedangkan ketua LPSE adalah kepala Kantor Komunikasi dan Informasi Kabupaten Maros yang bertugas memimpin operasional harian LPSE Kabupaten Maros.

Jadi, ada lima indikator transparansi yang terpenuhi dan sesuai dengan realita dilapangan dalam proses layanan pengadaan barang dan jasa pemerintah, 
diantaranya: mudah dipahaminya peraturan dan prosedur pelayanan, adanya audit independent, persyaratan teknis dan administrative pelayanan, akses informasi yang valid dan tepat waktu, serta adanya pejabat yang berwenang dalam pelaporan hasil pemenang lelang (appeal rights). Sedangkan dua indikator transparansi yang tidak terpenuhi adalah rincian biaya layanan yang tidak ada dalam $e$ procurement dandata informasi umum bisa secara transparan diakses akan tetapi data spesifik dan rahasia pokja atau ULP seperti alasan detail kenapa data-data hasil sanggahan, publikasi SPPJ dan sebagainya tidak bisa di tampilkan di website LPSE.

Sejalan dengan pandangan Kim (2007), tentang unsur-unsur transparansi meliputi: kejelasan (clarity) atau mudah dipahaminya peraturan dan prosedur pelayanan, aksesibilitas (accessibility) dalam arti akses informasi yang yang valid dan tepat waktu namun ada data yang juga dirahasiakan demi kepentingan panitia pengadaan, integrasi (integration) dalam arti adanya audit independent yang saling integrasi demi transparansinya pengadaan yakni dari inspektorat darah, BPK, dan audit melalui Whistleblower System dari LKPP, serta rasional (rationality) dalam arti adanya proses yang konsisten dalam pelayanan pengadaan, terstandarisasi oleh LKPP, formal dan legal hukum setiap proses pengadaan yang memunculkan pemenang tender, dan dapat diupgrade segala bentuk informasi pengadaan dengan sistem e-procurement.

Selain itu, penelitian ini menunjukkan bahwa dalam layanan pengadaan barang dan jasa pemerintah ada faktor-faktor yang mempengaruhinya yang membuat layanan pengadaan pemerintah menjadi terkendala. Dalam proses pengadaan barang dan jasa pemerintah khususnya di Kantor Komunikasi dan Informasi Kabupaten Maros bahwa ada beberapa faktor yang mempengaruhi transparansi dalam pengadaan barang dan jasa pemerintah, diantaranya:faktor komunikasi yakni penguasaan aturan pengadaan secara umum oleh panitia dan penyedia juga sangat penting hal ini agar tidak terjadi miskomunikasi atau misunderstanding antara kedua belah pihak dalam proses pengadaan barang dan jasa di Kantor Komunikasi dan Informasi Kabupaten Maros. Faktor teknologi yakni faktor teknis meliputi server, sistem SPSE yang selalu upgrade, koneksi internet dan peralatan lainnya yang menyangkut operasional teknis LPSE yang perlu dijaga dan ditingkatkan maintainance agar berjalan lancar dalam setiap proses lelang. Selain itu, kondisi LPSE 
Kabupaten Maros jaringan internetnya masih belum 100\% maksimal. Jadi koneksi jaringan yang stabil juga sangat berpengaruh pada lancarnya tahapan proses lelang yang sedang berlangsung. Faktor sumber daya manusia yakni faktor pengelola yang terdiri dari tim LPSE yang kapabilitasnya dan penguasaan atau pemahaman akan sistem yang ada oleh pihak terkait (peserta, pokja/panitia, ppk, inspektorat, auditor BPK) sehubungan dengan kemampuan mengikuti atau mengakses tahapan yang ada. Untuk SDM LPSE sendiri masih sangat minim dalam memberikan pelayanan dan operasional administrasi secara IT. Faktor Sikap Aparatur Pemerintah yakni para panitia lelang yang berstatus PNS masih syarat akan kemalasan, kurang loyal dengan waktu, dan kurang responsif terhadap tugas pekerjaannya. Sehingga dalam proses pengadaan barang dan jasa Kabupaten Maros ada panitia yang kinerja bagus dan ada juga yag kinerja buruk. Struktur Birokrasi Pemerintah yakni pengelola kebijakan LKPP dan LPSE merupakan unit pengadaan yang mana kantornya berada sama dengan Kantor Komunikasi dan Informasi Maros serta Ketua LPSE juga merupakan Kepala Kantor begitu juga pejabat LPSE lainnya merangkat jabatan dengan jabatan struktural Kantor Komunikasi dan Informasi.
Faktor keberterimaan masyarakat bisnis terhadap kebijakan transparansi yakni perusahaan-perusahaan yang bergerak dalam bidang IT sangat mudah dalam menerima kebijakan transparansi pengadaan ini, dengan adanya sistem $e$ procurement ini. Tetapi untuk perusahaan yang selama ini nyaman bermain secara manual tiba-tiba beralih ke sistem pengadaan secara online sangat susah untuk memahami alurnya sistem dengan benar. Faktor pengguna layanan LPSE yakni faktor penggunaLPSE yakni penyedia dan kelompok kerja ULP. Biasanya penyedia kurang faham IT dalam artian kadang tidak mengerti user dan password penyedia untuk mengikuti proses lelang. Sedangkan pokja kurang maksimal dalam menjalankan tahapan proses lelang karena pelatihan dari LKPP yang tidak terjadwal.

\section{SIMPULAN}

Proses layanan pengadaan barang dan jasa secara elektronik pada Kantor Komunikasi dan Informasi Kabupaten Maros cukup transparan karena semua mekanisme proses lelang menggunakan sistem online dan telah transparan secara sistemnya. Proses layanan pengadaan barang dan jasa telah mudah dipahaminya dan jelas akan peraturan dan prosedur pelayanannya, integrasi (integration) dari panitia pengadaan serta audit pengadaan 
dari inspektorat daerah, BPK, dan audit melalui Whistleblower System dari LKPP, serta rasional (rationality) dalam proses yang konsisten dalam pelayanan pengadaan, terstandarisasi oleh LKPP, formal dan legal hukum setiap proses pengadaan yang memunculkan pemenang tender, dan dapat diupgrade segala bentuk informasi pengadaan dengan sistem procurement.Tetapi, aksesibilitas (accessibility) informasi masih kurangdetail dan tepat waktu sesuai jadwal pengadaaan. Layanan yang kurang transparan pada akses data yang detail tentang evaluasi penawaran dan alasan detail dalam penentuan pengumuman pemenang oleh pokja, SPPJ dan tanda tangan kontrak hanya orang-orang tertentu yang bisa akses dan mengetahuinya secara detail dan jelas. Faktor-faktor yang mempengaruhi transparansi dalam pengadaan barang dan jasa pemerintah, diantaranya adalah: komunikasi panitia dengan penyedia; sumber daya yang tersedia baik faktor teknologimaupun faktor sumber daya manusia; faktor sikap aparatur pemerintah; faktor struktur birokrasi pemerintah; faktor keberterimaan masyarakat bisnis terhadap kebijakan dan faktor pengguna layanan LPSE. Kemudian saran penelitian bahwa perlu edukasi secara kontinyu kepada penyedia barang dan jasa (rekanan) agar mereka memiliki pemahaman yang sama tentang kebijakan e-Procurement dan kapasitas teknis untuk dapat mengikuti tender elektronik.

\section{DAFTAR PUSTAKA}

Andrianto Nico. 2007. Good eGovernment: Transparansi dan Akuntabilitas Publik Melalui $e$ Government. Malang: Bayumedia.

Asian Development Bank. 1999. "Governance: Sound Development Management".Asian Development Bank.

Creswell John W. 2010. Research Design Pendekatan Kualitatif, Kuantitatif, dan Mixed, Edisi Ketiga, Terjemahan oleh Achmad Fawaid. Yogyakarta: Pustaka Pelajar.

Dwiyanto Agus. 2006. Mewujudkan Good Governance Melalui Pelayanan Publik. Yogyakarta: Gadjah Mada Uiversity Press.

Herman Joffri. 2015. Akuntabilitas Publik Dalam Pengadaan Barang/Jasa Pemerintah Secara Elektronik (E-Procuremet) Di Kabupaten Toraja Utara. Tesis. Universitas Hasanuddin. Makassar.

Kim Pan Suk. 2007. How to Build and Sustain Transparency and Accountability in Public Sector Yonsei University, Seoul. Jakarta: UNDESA bekerjasama dengan Kementerian PAN, UNGC, dan UNDP.

Krina Lalolo Loina P. 2003. Indikator Dan Alat Ukur Prinsip Akuntabilitas, Transparansi dan Partisipasi. Jakarta: Sekretariat Good Governance Badan Perencanaan Pembangunan Nasional.

Moleong Lexi J. 2012. Metodologi Penelitian Kualitatif. Bandung: Remaja Rosdakarya. 
Sani Asrul. 2011. Evaluasi Penerapan EProcurement Pada Pemerintah Provinsi Sulawesi Selatan.Tesis. Universitas Hasanuddin. Makassar.

Sugiyono. 2011. Metode Penelitian Kualitatif. Bandung: Alfabeta.

Ratminto dan Winarsih. 2014. Manajemen Pelayanan Pengembangan Model Konseptual, Penerapan Citizen's Charter dan Standar Pelayanan Minimal

Cetakan XII. Yogyakarta: Pustaka Pelajar.

Smith Rex Deighton. 2004. Regulatory Transparency in OECD Countries: Overview, Trends a,d Challenges. Australian: Journal of Public Administration.

Peraturan Bupati Maros Nomor 12 Tahun 2013 Tentang Standar Operasional Dan Prosedur (SOP) Layanan Pengadaan Secara Elektronik (LPSE) Kabupaten Maros 